\title{
SABERES E PRÁTICAS SOCIOAMBIENTAIS NA PESCA ARTESANAL DO CARANGUEJO-UÇÁ NA AMAZÔNIA BRAGANTINA (PONTINHA DO BACURITEUA-PA)
}

Marcelo do Vale Oliveira ${ }^{1}$ Alexandre de Brito Alves ${ }^{2}$

\begin{abstract}
RESUMO
Nosso objetivo foi evidenciar os saberes relacionados com as práticas socioambientais dos tiradores de caranguejo da comunidade Pontinha de Bacuriteua em Bragança-PA. Para a compreensão desse modo de vida foi necessária uma abordagem qualitativa interdisciplinar sobre pesca artesanal e comunidades pesqueiras, englobando áreas do conhecimento como antropologia, sociologia e história. A metodologia aplicada foi composta de entrevistas semiestruturadas, auxiliada por observação direta. Os principais resultados foram a identificação de que os conhecimentos dos ciclos biológicos do caranguejo, dos movimentos das marés, das fases da lua, da composição físico-química do solo são instrumentos essenciais na captura do crustáceo em foco. Tais compõem-se de um conjunto de saberes que os tiradores aprenderam com e pelas gerações anteriores e que são colocados em práticas ao movimentarem-se em seus locais de trabalho, diariamente.
\end{abstract}

Palavras-chave: Saberes socioambientais. Pesca artesanal. Tiradores de caranguejo.

\section{SOCIO ENVIRONMENTAL KNOWLEDGES AND PRACTICES INVOLVED IN THE UÇÁ-CRAB FISHING IN BRAGANÇA-AMAZON (PONTINHA DO BACURITEUA-PA).}

\begin{abstract}
Our objective was to bright the knowledge related the socio-environmental practices of the crab pickers of the Pontinha de Bacuriteua community in Bragança-PA. To understand the way of life, an interdiplinary qualitative approach on artisanal fishing and fishing communities was necessary, encompassing areas of knowledge such as antropology, sociology and history. The applied methodology was composed of semi-structured interviews, aided by direct observation. The main results were the identification that the knowledge of the biological cycles of the crab, the movements of the tides, the phases of the moon, the physical-chemical composition of soil are the essential instruments in the capture of the crustacean in focus. Such are composed of a set of knowledge that the gunners learned with and for previous generations and which are put into practice when moving around their workplaces, daily.
\end{abstract}

Keywords: Socio-envirolmental knowledge. Artesanal fishing. Crab pikers.

Data da submissão 28. 08. 2020

Data da aprovação 07. 12. 2020

\section{INTRODUÇÃO}

Nosso objetivo é compreender sobre as práticas socioambientais referentes à pesca do caranguejo, de modo que para entender o êxito nos trabalhos é essencial, também,

\footnotetext{
${ }^{1}$ Doutor em Sociologia pela Universidade Federal do Pará (PPGSA/UFPA). Técnico em Assuntos Educacionais na Universidade Federal do Pará. E-mail: marcelomvo@ufpa.br

${ }^{2}$ Mestre em Sociologia, Programa de Pós-Graduação em Sociologia e Antropologia (PPGSA/UFPA). Discente do Doutorado em Sociologia (PPGSA/UFPA). E-mail: alexandrehistoria2010@yahoo.com.br
} 
identificarmos como os sujeitos constroem saberes, que são aperfeiçoados por seus corpos durante os longos anos de experiência empírica.

Os saberes e práticas locais, além de explicitarem os modos de vida e visões de mundo, também constituem domínios e instrumentos técnicos necessários para diversos grupos sociais em zonas litorâneas no Brasil conseguirem suas fontes de rendas, incluso os que reproduzem suas atividades no território da Resex Marinha Caeté-Taperaçu. Nesse sentido, esses grupos estabelecem uma relação de dependência com os territórios que constroem, se apropriam e dominam. Além da captura do caranguejo-uçá (Ucides cordatus), pescam turu, siri e peixes. Também participam de atividades agroextrativistas como a pequena agricultura. Este último fator caracteriza o que autores como Alex de Mello (1993) e Lourdes Furtado (1993) denominam: pescadores polivalentes.

Ressalta-se que o grupo social acompanhado, os tiradores de caranguejos da comunidade do Pontinha do Bacuriteua, município de Bragança, Nordeste do Estado do Pará, reproduz lógicas e práticas vinculadas ao Capitalismo, como a monetarização, a quantidade de caranguejos coletados (produção) vinculada aos ganhos auferidos, em fricção com o modo de vida baseado nos saberes tradicionais locais.

Essas práticas se dão no manguezal localizado em Bragança-PA, descrito por Ipojucan Campos (2012, p. 150) enquanto "[...] fonte de sobrevivência econômica para milhares de pessoas, ele significa lugar de "livre" atividade financeira que, inevitavelmente, reflui na cidade de Bragança”. A interpretação do pesquisador é que existem, no manguezal, dinâmicas socioculturais, quando o assunto "localiza-se nas estratégias de sobrevivência" (p. 155). Desta feita, é necessário interpretar o manguezal e sua estrutura como componente do humano e também do não-humano, caracterizando o que o economista equatoriano Alberto Acosta (2016) chama de "bem viver", no caso a partir da perspectiva das populações indígenas do Equador e da Bolívia.

É um lugar de constituição de territórios e territorialidades (LITTLE, 2004; HAESBAERT, 2007), "marcas de poder" e símbolos projetados pelos homens que diariamente estão dentro do ecossistema. O uso deste ambiente como fonte de sobrevivência e reprodução social é bastante antigo, pois antes da chegada dos europeus à Amazônia, os povos nativos já utilizavam os recursos do manguezal (SOFFIATI, 2004).

O manguezal como local necessário à sobrevivência desses grupos sociais e como território de suas identidades, modo de vida e pertencimento, dos que residem na zona costeira de Bragança foi identificado nas pesquisas de Alves (2015a, 2017b); Oliveira (2015); Oliveira (2013); Oliveira \& Maneschy (2014); Oliveira (2018) e Campos (2013). Os autores citados observaram os movimentos dos homens em tal ecossistema e as rotas de comercialização do caranguejo-uçá na PA-458 (Estrada que liga Bragança à praia de Ajuruteua e utilizada pelos trabalhadores para entrar no manguezal). A Estrada é utilizada, também, ao escoamento da produção de parte do pescado desembarcado na área costeira de Bragança, quais sejam: nas Vilas do Bonifácio, do Tamatateua, do Castelo, do Bacuriteua e nos portos de paradas, em pontes que se localizam na estrada.

A constatação do ecossistema como lugar essencial às atividades de populações que residem às proximidades das áreas de manguezais por parte da sociologia e de outras ciências humanas tem conduzido à produção de pesquisas e divulgação de seminários, palestras, artigos, ensaios, dissertações e teses que identificam e mostram o modo de vida desses grupos humanos. Os estudos de Maneschy (1993a); (2003b); Souza (2013); Oliveira (2015), Oliveira (2018) e Alves (2017) centram-se em aspectos socioeconômicos, tais como as transações entre tiradores e os marreteiros ${ }^{3}$ e nas identidades locais. Os estudos desses autores também mostram as atividades realizadas por mulheres e crianças no manguezal; as relações de gêneros dentro e

\footnotetext{
${ }^{3}$ Intermediários que compram dos tiradores e vendem ao consumidor e ou a outros marreteiros.
} 
fora do ecossistema; as questões simbólicas como a existência de "visagens"4 no local de trabalho; as técnicas e tecnologias utilizadas à pesca; o tempo de entrada e de saída à labuta e a alimentação dos trabalhadores.

Com a proposta em dar continuidade as observações e conclusões dos cientistas sociais, a pesquisa, em foco, intenciona compreender como um grupo social específico, tiradores de caranguejo da Pontinha do Bacuriteua, desenvolvem suas práticas socioambientais a partir dos saberes locais, utilizados à pesca do caranguejo-uçá na Amazônia, especificamente em Bragança.

Para isto, os procedimentos metodológicos decorreram do contato dos pesquisadores com habitantes da Pontinha do Bacuriteua. Nesta localidade, parte significativa da população vive da coleta e comercialização do caranguejo-uçá, estando o Bacuriteua entre as comunidades de maior produção pesqueira na região (DOMINGUES, 2008). Os pesquisadores mantiveram diálogos com os interlocutores, através, primeiramente de entrevistas informais, e posteriormente com entrevistas gravadas, feitas, também, digitação das falas dos atores.

Metodologicamente, para a compreensão desse modo de vida, foi necessária uma visão mais interdisciplinar sobre pesca artesanal e comunidades, englobando áreas de conhecimento como antropologia, sociologia e história. Nossa intenção foi o de dialogar com diferentes saberes para evitar que os limites de uma única abordagem impeçam o entendimento dos fenômenos analisados, pois trata-se de homens que há décadas mantém interações com o ambiente natural e que, sobre este, desenvolveram e partilham muitos saberes, sem os quais não seria possível a coleta do caranguejo.

Durante os anos de 2010 a 2017 os autores deste estudo tiveram contatos com pessoas que vivem na e da holocenose em foco. Os dados aqui discutidos advêm das pesquisas para a dissertação de mestrado de ambos. Somando as duas pesquisas, foram realizadas entrevistas semiestruturadas com trinta coletores de caranguejo, além de observação não participante das atividades dos tiradores de caranguejo. A pesquisa consistiu em observação direta e entrevistas semiestruturadas com trabalhadores do manguezal da comunidade Pontinha do Bacuriteua.

O desenvolvimento do artigo divide-se em dois tópicos. No primeiro, "Quem são os tiradores de caranguejo da Pontinha do Bacuriteua?", a intenção é apresentar os tiradores de caranguejo; o segundo denomina-se "Saberes e práticas socioambientais dos tiradores de caranguejo": onde analisamos os principais saberes e práticas dos tiradores sobre aspectos ambientais e o ciclo biológico do crustáceo. Neste, mostra-se como tais fatores repercutem na atividade e na escolha dos territórios. Esse segundo se subdivide nos subtópicos: "Técnicas e tecnologias e o regime de marés" ou seja, como são construídas tecnologias e as técnicas usadas a partir de um conhecimento empírico, no caso específico, o regime de marés; "A composição do solo e a flora do manguezal", discorre sobre como os conhecimentos dos tiradores sobre a estrutura física do bioma e como isso é importante ao êxito nas empreitadas diárias; e "A coleta do caranguejo: saberes e práticas", mostra-se e identifica-se como tiradores de crustáceo usam os conhecimentos locais em suas práticas empíricas diárias.

\section{QUEM SÃO OS TIRADORES DE CARANGUEJO DA PONTINHA DO BACURITEUA?}

Nesse tópico, evidenciaremos as principais características apresentadas pelo grupo acompanhado. As categorias principais trabalhadas no tópico são populações tradicionais e saberes locais. Essas escolhas se dão pela literatura científica disponível nas ciências sociais, a partir de pesquisas que observaram grupos similares, e que foram utilizadas nas dissertações feitas pelos autores.

\footnotetext{
${ }^{4}$ Trata-se de encantados, assombrações, fantasmas e fenômenos inexplicáveis que se manifestam em mangues, rios ou florestas, tais como a Mãe-d'água e a Curupira, por exemplo.
} 
As populações tradicionais locais têm seu modo de vida diretamente vinculado às atividades da pesca, mais especificamente à artesanal, e aos territórios que eles se apropriam. Antônio Carlos Diegues (2005) evidencia que a categoria população tradicional engloba uma diversidade de populações, entre as quais se destacam na Amazônia: os povos indígenas, os caboclos e os ribeirinhos. Esses grupos dominam saberes empíricos sobre rios, igarapés e manguezais e dos seres vivos encontrados nos territórios aonde desenvolvem suas atividades. Suas vivências são associadas às áreas rurais, com grande dependência do território que as cercam, tendo como premissas para os seus usos os ciclos (biológicos, climáticos, astronômicos, entre outros) para a produção e reprodução de seus modos de vida.

E uma das principais atividades reproduzidas na Pontinha do Bacuriteua é a pesca artesanal aqui entendida a partir de Diegues (2005), e refere-se a pescadores que se concentram nas regiões litorâneas, rios e lagos, possuindo um modo de vida baseado na pesca, mas exercendo outras atividades como: o extrativismo vegetal, o artesanato e a pequena agricultura. Especificamente, no Nordeste Paraense, destacam-se a coleta de mexilhão, turu, cipós, plantas medicinais, lenha, madeira para carvão, entre outros (FURTADO et al., 2006) como atividades entre os pescadores artesanais, o que ocorre na Pontinha do Bacuriteua, principalmente como função das mulheres.

Os tiradores de caranguejo acompanhados podem ser inseridos na categoria de pescadores artesanais, pois exercem suas atividades com base em conhecimentos empíricos sobre o ambiente em que atuam. Observando pela lente de Diegues (2005, p. 6, 7), pescadores artesanais têm:

[...] um modo de vida baseado principalmente na pesca, ainda que exerçam outras
atividades econômicas complementares, como o extrativismo vegetal, o artesanato e
a pequena agricultura. Embora, sob alguns aspectos, possa ser considerada uma
categoria ocupacional, os pescadores, particularmente os chamados artesanais,
apresentam um modo de vida peculiar, sobretudo aqueles que vivem das atividades
pesqueiras marítimas. Frequentemente, alguns grupos como os jangadeiros e praieiros
identificam-se primordialmente como pescadores. A unidade de produção é, em geral,
a familiar, incluindo na tripulação conhecidos e parentes mais longínquos. Apesar de
grande parte deles viver em comunidades litorâneas rurais, alguns moram em bairros
urbanos ou peri-urbanos, construindo aí uma solidariedade baseada na atividade
pesqueira [...].

Entretanto, no lugar desta pesquisa, os trabalhadores não se denominam pescadores e, sim, tiradores e/ou coletores. A observação de Oliveira e Henrique (2018) identifica que os mariscadores, pelas diferenças de suas atividades, incluso o recurso explorado, técnicas, instrumentos, produção e comercialização, não se consideram pescadores. É recorrente, inclusive, fazerem distinção entre suas atividades e a dos pescadores de rios, lagos e marés. $\mathrm{O}$ labutador do manguezal na percepção dos entrevistados exerce função diferente, pois tem outra especialidade, ou seja, outra forma de trabalho. A lida com o mangue é muito dificultosa em relação ao trabalho nas águas, visto que exige uma série de habilidades corporais tais como: o afã com as ferradas de insetos, os cuidados nas caminhadas e a esforços físicos nas caminhadas diárias (ALVES, 2020). Porém, observando do ponto de vista científico, não há equívocos em denominar os trabalhadores dos manguezais de pescadores artesanais, pois os mangues dependem das águas das marés para existir, são ecossistemas que se localizam entre águas de rios, marés e o solo, razão porque seu "terreno" é lamoso.

Das formas de coleta mais utilizadas pelos tiradores acompanhados, destacam-se o braceamento e o gancho. Oliveira (2013) as descreve:

A primeira é a mais corrente. $\mathrm{O}$ tirador introduz seu braço na galeria do caranguejo até alcançá-lo e trazê-lo à superfície. Embora possa parecer "fácil", simples coleta, ele praticamente tem que se deitar no solo de maneira a que seu braço possa penetrar mais 
fundo na toca. Para protegerem as mãos e o braço, é comum utilizarem espécies de luvas feitas de tecido resistente, agregando proteção especial de tecido para os dedos. Já o gancho é uma prática mais recente e sua difusão decorre da busca de maior produtividade e da maior concorrência na exploração do recurso. Consiste da utilização de uma barra de madeira, geralmente o cabo de uma vassoura, com um pedaço de ferro em formato de gancho na extremidade, que é introduzido nas galerias dos caranguejos que estão mais profundos, principalmente em áreas de sedimentação lamosa, popularmente conhecida como "tijuco" (OLIVEIRA, 2013, p. 61).

Outra característica importante para a reprodução da pesca artesanal e dos saberes tradicionais é a transmissão geracional, via oralidade, geralmente de pai para filho, e que darão o suporte necessário para o desempenho na atividade, sobrevivência no mangue, sustento da família e reprodução social do grupo, ou seja, são saberes necessários sobre os ecossistemas para o desenvolvimento das atividades extrativistas (OLIVEIRA, 2013; OLIVEIRA; MANESCHY,2018; OLIVEIRA, 2018). Outros autores (CAMPOS, 2013; MANESCHY, 1993) também ressaltam a transmissão geracional da profissão como fator decisivo para a reprodução social dessas atividades e modos de vida. Em Oliveira (2013), os dados apontam que todos os pais dos entrevistados trabalharam em atividades ligadas à pesca artesanal e à agricultura (geralmente lavoura) foram, na maioria das vezes, iniciados pelo pai no manguezal. Eis um relato típico: "Toda a vez que ele [o pai] ia [ao manguezal] eu ia com ele" (Z., 30 anos, entrevistado em 08.08.2011).

E nas coletas de dados realizadas por Oliveira (2013), junto aos tiradores de caranguejo atuantes nas áreas abrangidas pela Resex, os discursos sempre evidenciam o grande saber acerca dos fenômenos naturais e seu uso nas atividades extrativistas pelos pescadores artesanais. Decerto, o saber empírico aprofundado das relações entre animais, plantas, marés, do ecossistema e território, é fundamental para a reprodução social das populações e de suas atividades extrativistas.

Outros resultados: os tiradores de caranguejo da Pontinha do Bacuriteua acompanhados se caracterizam por início na atividade extrativista do caranguejo ainda durante a adolescência; apresentam alta evasão escolar; se autorrepresentam como especialistas na atividade, embora também atuem em atividades complementares e têm dificuldade em serem reconhecidos como categoria profissional; enfrentam problemas de saúde geralmente com alguma relação com as condições de seu trabalho; seu regime semanal de trabalho ocorre de terça a sábado, com folga geralmente no domingo e segunda-feira.

Desse modo, temos uma breve caracterização de questões colocadas no cotidiano desses homens e que nos ajudam na compreensão, a seguir, de como são construídos, quais sentidos e como são realizadas as práticas socioambientais em articulação com os saberes locais.

\section{SABERES E PRÁtICAS SOCIOAMBIENTAIS DOS TIRADORES DE CARANGUEJO}

O objetivo deste tópico é analisar os principais saberes e práticas dos tiradores sobre aspectos ambientais e o ciclo biológico do caranguejo, mostrando como tais fatores repercutem na atividade e na escolha dos territórios. As categorias principais trabalhadas são saber tradicional local e práticas socioambientais. $\mathrm{O}$ trabalho com essas categorias se deu em virtude da literatura científica disponível nas ciências sociais, a partir de pesquisas que observaram grupos similares, que foram utilizadas nas dissertações feitas pelos autores e das observações feitas no acompanhamento das atividades dos tiradores de caranguejo da Pontinha do Bacuriteua. Nossa intenção é de articular essas categorias entre si e com os dados empíricos, evidenciando os saberes e práticas reproduzidas acerca dos saberes e práticas socioambientais. 
Os tiradores de caranguejos constroem suas cosmovisões pela relação empírica com natureza e sociedade, seus modos de vida, formas de organização social e para a prática das atividades extrativistas e sentidos para as relações sociais estabelecidas entre si e com os outros, o que aqui denominamos de saber tradicional local.

Para a compreensão desse saber torna-se fundamental a territorialidade, no sentido do controle de espaço, dos recursos disponíveis e para a defesa dos territórios destinados às atividades extrativistas (BEGOSSI, 2004). Assim, para a autora, os pescadores artesanais criam "marcos" e "marcas" delimitando pontos de pesca, referências no mar e na terra, importantes nos processos relacionados ao lugar pesqueiro e à tomada de decisão de localização, formas de escolha e apropriação. Há a construção de uma racionalidade própria dos grupos, que nesse processo de ocupação os dotam de sentidos culturais, construindo o reconhecimento e sua apropriação social, a partir das práticas identitárias e culturais do grupo social (SILVA, 2007; FURTADO, 1997).

No caso de manguezais onde atuam os tiradores da Pontinha do Bacuriteua, a partir da não existência de territórios delimitados de forma fixa em áreas de coleta do caranguejo, como afirmado por Oliveira (2013) e Oliveira; Maneschy (2014), teremos territorialidades não fixas e os saberes dos extrativistas, eivados em suas percepções do ambiente; do caranguejo e dos peixes, irão nortear suas escolhas durante o desenvolvimento da atividade extrativista.

Essa não fixidez vincula-se a caracterização dos mangues, enquanto, categoria de base comum de recursos ou territórios comuns, nos quais a apropriação dos recursos ocorre em comum com determinados grupos, não significando livre acesso (MCKEAN; OSTROM, 2001). Essas últimas autoras consideram a propriedade comum uma forma de propriedade privada, não no sentido de ser dividida em parcelas com donos definidos, mas sim apropriada por direito por um grupo, grupos e/ou comunidades bem definidas, podendo ter um caráter exclusivista e de exclusão de outros grupos ${ }^{5}$.

Apesar dessa não fixidez, no contexto dos grupos sociais evidenciados, para que os territórios sejam apropriados há a necessidade do uso das territorialidades. Elas dizem respeito aos processos pelos quais o grupo ou grupos sociais envolvidos institucionalizam a apropriação e o controle, constituindo o reconhecimento social do território. As territorialidades são as regras sociais e os padrões pelos quais grupos sociais se apropriam de seus espaços de vida e trabalho, reivindicando-os como seus e mobilizando-se em sua defesa contra grupos rivais (SILVA, 2011; ABREU, 2010; BEGOSSI, 2004). ${ }^{6} \mathrm{O}$ uso dos termos no plural indica a heterogeneidade desses processos dentro de um grupo e/ou entre grupos diferentes, que diferem nas perspectivas sobre territórios e práticas inerentes ao seu uso (OLIVEIRA, 2013; OLIVEIRA; MANESCHY, 2014).

A partir dos territórios e territorialidades, os saberes tradicionais locais são usados e influem nas tecnologias e técnicas construídas e utilizadas nas atividades extrativistas.

\footnotetext{
${ }^{5}$ A principal descoberta de Oliveira (2013) e Oliveira \& Maneschy (2014) é que os tiradores de caranguejo da Pontinha do Bacuriteua possuem uma dupla percepção sobre a instituição de territórios no manguezal. A primeira é de que o manguezal é uma área de livre acesso e de recursos comuns, sem propriedade privada, sem a existência de territórios delimitados e de acesso exclusivo de um determinado grupo e excludente de outros, ou seja, os tiradores não instituem territórios permanentes, pois “o manguezal é de todo mundo". Essa percepção se manifesta antes da definição sobre qual área será explorada no dia. A segunda percepção é de que no momento da chegada e ocupação de uma determinada área pelos tiradores, elas se tornam territórios temporários, ou seja, a partir do momento em que os trabalhadores iniciam suas atividades naquela área apropriada temporariamente os territórios aparecem, com acesso apresentando algumas restrições, observação de regras no seu uso, disputas e conflitos. O direito temporário a esse território dura o tempo em que efetivamente o grupo está explorando os recursos naturais da área, sendo geralmente diário ou durante algumas horas. Nesse sentido, o manguezal "é de quem chegar primeiro". Por fim, há fluidez entre as duas percepções, pois elas se alternam constantemente, dependendo da situação dos tiradores em determinado momento.

${ }^{6}$ O trabalho de Silva (2011) interpreta as tradições e modernidade relacionando o conhecimento ecológico local, o manejo na pesca e os conflitos pesqueiros em comunidades no rio Negro, Brasil.
} 


\subsection{TÉCNICAS E TECNOLOGIAS E O REGIME DE MARÉS}

As tecnologias e técnicas são construídas e usadas a partir de um conhecimento empírico, no caso específico destacamos o regime de marés. A escolha da técnica depende de alguns fatores, tais como: intenção de aumento da produção, a condição do solo e a profundidade em que está o caranguejo nas galerias. Não foram observadas diferenças entre tiradores jovens e adultos quanto às práticas de coleta. Porém, essa evolução técnica - o uso do gancho - não é acompanhada de melhores condições para o desenvolvimento das atividades, o que acarreta falta de roupas mais adequadas para adentrar no manguezal, equipamentos e instrumentos que proporcionem condições para o desenvolvimento da atividade sem impactar o ecossistema (MANESCHY, 1993).

O clima na região caracteriza-se, tendencialmente, por um período bastante chuvoso, que ocorre de dezembro a maio, e um período mais seco, com muito sol e calor, que acontece de junho até novembro (GLASER; CABRAL; RIBEIRO, 2005). Diegues (2005) reafirma a importância da estacionalidade como elemento para a organização social e a identidade das populações tradicionais que vivem da pesca artesanal. A vida destas e suas atividades econômicas não podem ser desvinculadas do seu saber e dependência das duas estações: das águas e da seca.

Glaser, Cabral e Ribeiro (2005) relacionaram a importância da estacionalidade com as atividades econômicas desenvolvidas nas comunidades onde vivem os tiradores. Eles diversificam as atividades buscando meios complementares de garantir a renda familiar, principalmente no período de maior precipitação, também pela influência do período reprodutivo do caranguejo, sendo que a proximidade das comunidades com os recursos naturais no seu entorno facilita essa diversificação. Já no período mais seco e com maior abundância do caranguejo a extração se intensifica.

A maioria dos entrevistados indicou que a presença de chuva, principalmente aquelas torrenciais e associadas às marés, tem relação direta com a baixa produtividade nesse período. Um entrevistado sobre essa relação assim se manifestou: "Quando chove grosso demora mais pra vazar a maré" (M., entrevistado em 08/08/2011). A chuva prolonga a submersão das áreas do manguezal, reduzindo as possibilidades de coleta do caranguejo. Resta ao tirador aguardar a diminuição da chuva e a vazante da maré. "No inverno, quando chove muito, não presta, a gente trabalha e não pega nada. Na chuva fina ainda pega, na chuva grossa não pega" (M., entrevistado em 08/08/2011).

Os tiradores afirmam que quando chove no manguezal as áreas de tijuco são "lavadas" e ficam mais "moles", por se constituírem de sedimento lamoso, facilitando o caranguejo em se "enterrar" no solo, dificultando a coleta via braceamento e, em alguns lugares, mesmo com o "gancho". O deslocamento dos tiradores nessa condição é difícil, principalmente, para carregar os caranguejos capturados de volta para a embarcação, tarefa que se torna extenuante. Também é necessário ressaltar que o período de chuva coincide com um dos ciclos biológicos do caranguejo indicados pelos tiradores como de baixa produtividade: o período de reprodução (OLIVEIRA, 2013).

O grupo faz articulações entre as condições de estacionalidade com a escolha dos territórios para a atividade, com os seguintes aspectos: tendência de escolher áreas com a presença de mais areia, devido à dificuldade que os caranguejos têm em se "enterrar" nas galerias, ficando mais rasos e facilitando sua coleta; tendência de escolher territórios mais próximos das margens dos furos e igarapés, também denominadas pelos tiradores de caranguejo de cabeceiras, evitando o deslocamento para áreas mais afastadas e que possuem maior presença de sedimentação lamosa, para que não percorra grandes distâncias. Há, também, dificuldade 
em visualizar as "áreas esbandalhadas"7 e/ou em "descanso", devido à submersão das áreas pela chuva, dificultando o reconhecimento dos territórios recém-utilizados; e, por fim, aumento da característica polivalente do grupo.

Já na estação seca há mais facilidade no trabalho. O caranguejo tem mais dificuldade para penetrar mais fundo no solo, que não está tão "mole". O discurso de facilidade na coleta também evidencia que a "safra" do caranguejo ocorre em outubro, quando é menor o índice pluviométrico. Nos trechos abaixo sobressai a pouca profundidade dos caranguejos nas galerias. "Agora no verão fica raso, em agosto, setembro, outubro. A lama engrossa e ele [o caranguejo] não cava. (S. C., entrevistado em 13/07/2011)".

Os principais saberes levados em consideração nas práticas socioambientais no período mais seco são: os territórios com sedimentação lamosa estão mais "secos" e com menor influência das marés e os caranguejos, também, apresentam dificuldade em se "enterrar" nas galerias, ficam mais rasos e facilitam sua coleta; há facilidade em visualizar as "áreas esbandalhadas" e/ou em "descanso", propiciando o reconhecimento dos territórios recémutilizados; e, por fim, a quantidade de galerias e o tamanho da sua circunferência são primordiais na escolha dos territórios, pois estão relacionadas com uma possível grande quantidade de caranguejos disponíveis e pela valorização dos machos graúdos, discernível pelo maior tamanho das galerias. Portanto, como afirma Oliveira (2013), a estacionalidade tem implicações, junto às marés e ao ciclo biológico do caranguejo, na produtividade da coleta do caranguejo.

O regime de marés também funciona como regulador das atividades dos tiradores. Schmiegelow (2004, p.119) apresenta a conceituação científica de maré como um fenômeno regular no meio marinho caracterizado pelas oscilações nos níveis das águas, resultado da influência gravitacional exercida pelo sol e, sobretudo, pela lua, originando elevações e reduções de níveis das águas do mar. Geralmente, o seu movimento ocorre de doze em doze horas, duas vezes ao dia, constituindo duas enchentes da maré, conhecidas como preamar, e duas vazantes da maré, denominadas baixa-mar. $\mathrm{O}$ autor também discorre sobre as marés de quadratura, que ocorrem nas fases da lua minguante e da lua crescente e são responsáveis pelas menores amplitudes de maré. Já as marés de sizígia, que ocorrem nas fases da lua nova e lua cheia, são responsáveis pelas maiores amplitudes de maré.

Outra definição de maré é feita por Baptista Neto, Ponzi; Sichel (2004) que agrega às influências gravitacionais da lua e do sol, as forças ligadas ao movimento da Terra.

As marés são formadas pela ação combinada de forças de atração gravitacional entre
a Terra, Lua e por forças centrífugas geradas pelos movimentos de rotação em torno
do centro de massa do sistema Sol-Terra-Lua que se localiza no interior da Terra, a
uma distância de um quarto do raio terrestre, as forças estão em equilíbrio impedindo
que a lua seja atraída para a superfície da Terra (BAPTISTA NETO; PONZI;
SICHEL, p.190).

Assim como Schmiegelow (2004), Baptista Neto, Ponzi; Sichel (2004) colocam que durante um dia qualquer ponto da terra passa duas vezes pela enchente e vazante da maré, sendo que o sol é responsável pelas variações das marés de sizígia e de quadratura. Os autores também mostram as influências das marés nas zonas costeiras, caso das áreas exploradas pelos tiradores da Pontinha do Bacuriteua, que invadem os estuários e baías, submergem os manguezais, e são também responsáveis pela manutenção da diversidade biológica dessas áreas, transportando sedimentos e modelando a linha da costa.

\footnotetext{
${ }^{7}$ As áreas esbandalhadas são pontos dentro do manguezal que foram recentemente explorados, onde os tiradores coletaram caranguejo, e que se apresentam "pisoteadas", com marcas visíveis de que outros trabalhadores "mexeram" naquele local, portanto encontram-se esbandalhadas e sem muitos caranguejos graúdos (OLIVEIRA, 2013; OLIVEIRA; MANESCHY, 2014).
} 
Para os tiradores de caranguejo, as marés influenciam diretamente no seu trabalho, pois nas marés de maior amplitude é maior a tendência de submersão do solo do manguezal pelas águas, o que dificulta a coleta de caranguejo. Por conta disto, os trabalhadores aguardam a vazante da maré para executar suas atividades. Nas de menor amplitude, as de quadratura, quando o solo do manguezal tem a tendência menor de ser "invadido" pelas águas dos rios e do mar, as coletas são realizadas com maior facilidade, o que possibilita o aumento da produtividade.

Observou-se que os tiradores da Pontinha do Bacuriteua utilizam os termos lançante e maré de quarto para se referir às marés de sizígia e quadratura, respectivamente. Os tiradores da Pontinha do Bacuriteua afirmam que a etapa de marés lançantes tem início a partir de um ou dois dias após as luas de quarto minguante e quarto crescente e se estendem até um ou dois dias após as luas nova e cheia, então recomeça o período de marés de amplitude decrescente, as de quarto. Durante as lançantes, a cada dia a maré aumenta de amplitude, até chegar aos dias de maiores marés, que alguns tiradores se referem como "cabeças de lanço". O manguezal fica submerso dificultando o trabalho, quando eles não conseguem visualizar bem as galerias, consequentemente seu diâmetro e, também, perceber se esses territórios foram recém-usados ("esbandalhados"): "Maré lançante, crescendo, fica mais complicada [a coleta]" (S. L., entrevistado em 13/07/2011).

Como já afirmado por Maneschy (1993), a dificuldade de coletar caranguejos durante as cheias da maré repercute na diminuição da produção. Os tiradores da Pontinha do Bacuriteua percebem as diferenças diárias no comportamento da maré, pois observam que a enchente atrasa em uma hora a cada dia. Esse movimento influencia na quantidade de horas que ficam no manguezal, haja vista que eles têm de aproveitar as horas de vazante durante o dia claro para poderem trabalhar. Desse modo, se a enchente começar a ocorrer mais próxima do meio dia, resta-lhes pouco tempo para que ela vaze antes que anoiteça, obrigando os tiradores a sair mais cedo do mangue, diminuindo sua produtividade. Seus turnos de trabalho diários, portanto, variam conforme esses fluxos das marés.

\footnotetext{
A gente sabe quando [a maré vai encher]. Ela vai modificando, 1 hora, 2 [horas] de diferença. Cada dia tarda uma hora [para encher]. (C., entrevistado em 08/08/2011)". O cara é acostumado na maré e sabe quando enche. É uma hora mais por dia. Fica deitado, pescando no barco [esperando a maré vazar] (M., entrevistado em 08/08/2011)
}

A fala a seguir indica a variação no horário de trabalho em função do horário da vazante: "Conforme a maré saí do porto de lá 8 horas, fica esperando a maré escoar e entra (no mangal), sai 3, 4 horas (da tarde). (S. L., entrevistado em 13/07/2011)".

$\mathrm{Na}$ adaptação ao horário da maré, eles também procuram atender aos horários do mercado. Daí o fato de estarem cedo pela manhã posicionados próximo ao local escolhido, aguardando na margem do rio ou igarapé o momento em que podem adentrar e dar início ao trabalho. "Tem que esperar vazar a maré. Tem horas que 10 horas a maré vaza, tem dia que meio dia e a gente vai até 5 hora trabalhando. O cara tem que esperar ela vazar" (M., entrevistado em 08/08/2011).

Contudo, nos dias em que a maré enche mais cedo, final da madrugada e início da manhã, mais cedo será sua vazante, deixando mais tempo disponível para o trabalho, garantindo uma captura maior; nessa situação os trabalhadores retornam do manguezal no final da tarde e início da noite. "Sai cedo [o tirador do manguezal] quando enche tarde. Quando chega [de manhã] e ela tá cheia espera vazar" (Z., entrevistado em 08/08/2011).

As marés de quarto, de menor amplitude, na percepção dos tiradores não "lavam" o manguezal, ou seja, não submergem o solo, propiciando aos tiradores o desenvolvimento de suas atividades sem a premência do tempo, como ocorre durante as lançantes. "A maré de 
quarto, porque ela não lava [inunda] o mangal, eles [caranguejos] fica mais raso" (F., entrevistado em 18/07/2011).

Essa não submersão do manguezal torna o solo menos encharcado, "mais duro" e, como afirmado abaixo, com o caranguejo tendo dificuldade em cavar suas galerias. A primeira citação relaciona a maré lunar e a estação do ano como fatores que influenciam no seu trabalho e sua preferência pela maré de quarto: "É na maré de quarto. No inverno fica ruim que a lama fica mole e ele (caranguejo) cava" (S. C., entrevistado em 13/07/2011).

Em suma, no discurso dos tiradores é sempre evidenciado o saber acerca dos fenômenos naturais. É comum a expressão "a gente sabe", colocada para demonstrar a experiência adquirida na atividade e a vivência com o ambiente natural e seus fenômenos. A organização e o desenvolvimento do trabalho diário dependem desses saberes. Outros aspectos do ambiente também vão influir, a partir dos saberes, na atividade de tiração de caranguejo, como a composição do solo e a flora do manguezal.

\subsection{A COMPOSIÇÃO DO SOLO E A FLORA DO MANGUEZAL}

Em relação ao ambiente, os tiradores da Pontinha do Bacuriteua necessitam de saberes acerca da composição do solo e da flora para a escolha das áreas de trabalho. Essa escolha influencia na produtividade e no tipo de caranguejo que é coletado. Com isso, existe um mapeamento mental das áreas segundo essas características e, dependendo das circunstâncias do momento, será feita a escolha e esses elementos serão considerados.

O solo do manguezal é dividido pelos tiradores em "areal" e "tijuco". Nas áreas com predominância de areia, as marés que submergem o manguezal transportam esse elemento para dentro do mangue, por isso sua presença é mais constante nas cabeceiras dos furos e igarapés e em áreas próximas à praia de Ajuruteua.

No "tijuco" há predominância de sedimentação lamosa. Esses solos ficam em regiões mais centrais no manguezal, tendo como referência sua distância em relação aos rios e igarapés. O "tijuco" é subdividido em "tijuco mole" e "tijuco duro". Este último é caracterizado pela presença de pneumatóforos ${ }^{8}$, conhecidos pelos tiradores por siribal. São áreas com menor possibilidade de atolamento devido à retenção de sedimentos pelos pneumatóforos, tornando o solo mais "duro"; já o tijuco mole ocorre em áreas sem pneumatóforos, cuja tendência é, então, a][ de atolamento do tirador em seu deslocamento no manguezal.

A composição do solo é importante na percepção dos tiradores acerca das possibilidades de sucesso na coleta, pois nas áreas com maior concentração de areia caranguejos têm maior dificuldade de penetração no solo, o que facilita a coleta no braço. Já nas áreas com maior concentração de tijuco, o caranguejo consegue penetrar mais facilmente e mais profundamente nas galerias, o que dificulta a coleta no braço. Essas características do solo vão influir na técnica de coleta, por exemplo, os tiradores usam o gancho preponderantemente no "tijuco mole", pois os caranguejos estão mais fundos pela facilidade em cavar suas galerias. É o que afirma o tirador quando compara os dois tipos de elementos.

A gente já sabe, num ponto e outro [revezam os locais de coleta], sempre na parte de mais areia, fica mais fácil, parte de tijuco [sedimentação lamosa] fica mais difícil, fica mais fundo [o caranguejo], o caranguejo fica mais ou menos dois metros no fundo (S. L., entrevistado em 13/07/2011).

Porém, outros tiradores afirmaram que, geralmente, as cabeceiras estão "esbandalhadas", o que ocorre quando o lugar foi recentemente explorado por tiradores, pela maior facilidade de chegar nelas. Há relatos de que os tiradores têm que adentrar o manguezal

\footnotetext{
${ }^{8}$ Os pneumatóforos são os sistemas radiculares que permitem a fixação das árvores de Avicennia germinans e também atuam como raízes respiratórias (FONSECA, 1995).
} 
entre um e dois quilômetros para efetuar as coletas: "Vê esbandalhado [o local da coleta] nem pensar (M., entrevistado em 08/08/2011)".

Também deve levar em conta que os rios e igarapés são os principais meios de acesso ao manguezal. Nas áreas mais próximas desses cursos de águas há tendência de escassez de recursos, tanto pela facilidade no acesso, quanto pela interferência do regime de marés nesses locais. Assim, é mais difícil encontrar caranguejos machos e graúdos, havendo a necessidade de adentrar o manguezal e buscar as áreas de tijuco, como mostra o trecho abaixo: "Mais dentro do mangal, tem mangal que a gente anda mais longe. Na beira do rio tá mais esbandalhado e mais dentro é mais raso o caranguejo (C., entrevistado em 08/08/2011)".

Portanto, a avaliação das áreas de trabalho leva em conta, também, a composição do solo. Dependendo da necessidade dos tiradores, do regime das marés, do ciclo biológico do caranguejo e da estacionalidade será realizada a escolha de qual área é mais propícia naquele momento.

Em relação ao solo, há sinais deixados por outros tiradores que são percebidos e indicam a utilização ou não daquele trecho do manguezal. Domingues (2008) e Reis (2007) afirmam que os tiradores observam os sinais existentes nesse trecho e quando detectam que está "mexido" ou "esbandalhado" geralmente decidem por não o utilizar e saem em busca de outros espaços sem sinal de uso recente.

Outra prática importante é o descanso das áreas de coleta. Após o uso de uma área, os tiradores dão um intervalo de tempo, uma espécie de pousio, para o retorno. Domingues (2008) conceitua essa prática de descanso como uma forma de manejo e em sua pesquisa percebeu que o intervalo de tempo varia bastante. Reis (2007) afirma que os tiradores não retornam no dia seguinte ao local do dia anterior, mas em dias alternados. Nas entrevistas no Bacuriteua, o intervalo de tempo para o descanso das áreas, de acordo com os tiradores, varia de semanas a até meses.

O descanso tem o intuito de permitir que os caranguejos repovoem a área e/ou aflorem das galerias, tornando-os mais "rasos". Os tiradores afirmam que todo dia exploram uma área diferente: "Não, a gente vamos em outro lugar, cada dia em um lugar. Passa um mês, dois meses pra voltar [a uma área já utilizada]. Se for de novo lá, o bicho tá fundo" (C., entrevistado em 08/08/2011)".

De acordo com os tiradores, quanto menor o espaço de tempo entre uma coleta e outra na mesma área menor a produtividade e o tamanho dos caranguejos, por isso um tempo maior é recomendado. "Em uma semana, o cara vai hoje e na outra semana vai de novo, mas não pega muito não (Z., entrevistado em 08/08/2011)".

Além da facilidade dos caranguejos para cavar as galerias que se localizam no tijuco mole, há mais um fator percebido pelos tiradores que favorece a concentração de caranguejos machos, graúdos: sua alimentação das folhas do Mangueiro (Rhizophora Mangle). Quando os tiradores fazem referência ao mangueiro destacam suas raízes aéreas, denominando-as de "raizal". Domingues (2008), sobre o saber dos tiradores acerca da flora do manguezal, afirma:

Os coletores demonstraram possuir um conhecimento sobre as populações de caranguejos e os bosques de mangue. Segundo eles há manguezais que são berçários, pois há grande quantidade de caranguejos pequenos e fêmeas. Mas existem bosques em que o caranguejo é mais raso ou mais fundo (a relação raso ou fundo corresponde a profundidade da toca), há também locais onde o caranguejo é graúdo. Também os tiradores associam as características da população de caranguejo às peculiaridades do sedimento e da espécie arbórea dominante no bosque. Os manguezais denominados areais (nomenclatura utilizada para o sedimento com maior presença de areia), normalmente possuem caranguejos menores e flora dominada por siribeiras (Avicennia germinans) e menos frequentemente tinteiras (Laguncularia racemosa). Em contrapartida, há locais onde predomina o tijuco (nomenclatura utilizada para o sedimento com maior presença de silte e argila), onde o caranguejo é maior e há 
dominância de bosques de mangueiro (Rhizophora mangle) (DOMINGUES, 2008, p.33).

Os tiradores da Pontinha do Bacuriteua fazem a mesma classificação sobre as árvores baseada no conhecimento ecológico local citado por Domingues (2008) e eles também estabelecem a relação entre o raizal (Mangueiro) e o caranguejo cabelo branco, que se trata do caranguejo-uçá (Ucides Cordatus). Há, na percepção deles, preferência dos caranguejos pelas folhas dessa árvore, como afirmado abaixo: "Tem na areia caranguejo bonito, gordo, cabelo branco e tem o da lama. Muito caranguejo no raizal (S. C., entrevistado em 13/07/2011)".

A composição do solo, relacionada com as árvores e com o tipo de caranguejo requerido pelo mercado se apresenta como mais um fator do ecossistema cuja percepção dos tiradores de caranguejo da Pontinha do Bacuriteua levam em conta no momento da escolha das áreas de coleta e a instituição dos territórios temporários. Por fim, além de todos esses saberes construídos a partir de uma "leitura" realizada pelos tiradores acerca do ecossistema, também temos construções sociais sobre o ciclo biológico do caranguejo que afetam sua coleta.

\subsection{A COLETA DO CARANGUEJO: SABERES E PRÁTICAS}

Neste tópico discutiremos como os tiradores de caranguejo da Pontinha do Bacuriteua percebem os seguintes aspectos do caranguejo-uçá: ciclo biológico, sexo e os tipos coletados.

Vale recorrer novamente a Domingues (2008, p.34-35) que discute sobre o ciclo biológico anual do caranguejo, a partir da percepção dos tiradores da península bragantina, ressaltando três fases principais: a "andada"; a troca da carapaça, também conhecida como "troca da camisa"; e a "safra".

Durante os meses de janeiro a abril ocorre a andada, também conhecida como "souatá", que é o período reprodutivo da espécie, quando os caranguejos estão fora das galerias, "andando" pelo solo do manguezal. Esse fenômeno ocorre em determinadas fases da lua durante esses meses. Há diferenças, pois nos três primeiros meses há o predomínio dos machos fora das galerias e, no mês de abril, há o predomínio da fêmea (condurua) no solo. Os tiradores referemse a essa andada das fêmeas como o "souatá das conduruas".

A partir de junho e mais intensamente em julho se inicia a troca da carapaça ou troca da "camisa" do caranguejo, quando ele "fica de leite", impróprio para o consumo e suas galerias são "tapadas" pela própria espécie. A troca vai até final de agosto, ou início de setembro.

De outubro em diante inicia o período de "safra" e, progressivamente, de engorda do caranguejo, quando a produtividade dos tiradores é maior e diretamente proporcional à oferta de caranguejos. Em resumo, temos a seguinte configuração do ciclo biológico do caranguejo na percepção dos tiradores.

Maneschy (1993, p.43), referindo-se aos tiradores do Município de São Caetano de Odivelas, resumiu de maneira muito semelhante ao saber dos tiradores sobre o ciclo biológico do caranguejo e sua produtividade. De acordo com a autora, no período reprodutivo do caranguejo há uma intensificação da coleta do crustáceo, que se torna "fácil" para ser coletado na visão dos tiradores, pois os caranguejos estão fora das galerias e mais expostos. Essa condição colabora para que muitas pessoas das comunidades próximas do mangue adentrem, incluindo mulheres e crianças pequenas, para apanhar os caranguejos, sendo que no caso das crianças, geralmente, é visto como um período propício para a transmissão dos saberes sobre a prática da coleta.

Essa ideia de que o caranguejo se torna presa fácil nesse período é compartilhada também por Souto (2007, p.77) que, em estudo realizado no município de Acupe, no Estado da Bahia, coloca essa prática, na visão do IBAMA, como grande ameaça aos estoques de caranguejos-uçás existentes na região. Outra percepção dos tiradores sobre o comportamento do caranguejo durante a andada é a suposta "loucura" dos bichos, que ficam "perdidos" no 
manguezal; no dizer de um trabalhador entrevistado por Souto (2007, p.74), o caranguejo "fica tudo doido aqui no mangue".

De acordo com os tiradores, a andada ocorre nos primeiros quatro meses do ano, sendo dividida em primeira andada que ocorre de janeiro a março quando macho e fêmea estão se reproduzindo e acontecendo no mês de abril a desova das fêmeas no manguezal, também conhecido por andadas das conduruas. "Final da andada fica buchuda. Março, abril é a derradeira andada, a da condurua, só da condurua. Janeiro é a primeira andada, eles ficam namorando. (S. C., entrevistado em 13/07/2011)".

Os tiradores relataram que há muita dificuldade durante esse período, principalmente durante a semana em que o IBAMA proíbe a coleta do caranguejo. Seus relatos compreendem que as políticas públicas e sociais voltadas especificamente para o período do defeso não levam em conta o contexto em que vivem. Por exemplo, a cesta básica que foi distribuída em um determinado ano pelo IBAMA foi considerada de má qualidade e com produtos que não fazem parte da dieta local. As decisões políticas são vistas como tomadas de cima para baixo:

$\mathrm{Na}$ andada fica difícil, porque a gente não vai (Z., entrevistado em 08/08/2011).

Proíbe, fica sem pegar, os homem [técnicos do IBAMA] tão na estrada pra cima e pra baixo. A gente dá um jeito na boia e vai passando. Fica uma semana sem pegar. Uma vez deixaram uma cesta básica com uma farinha branca. Passava um dia no fogo e a farinha pulava na panela [reclamação sobre os produtos da cesta] (G., entrevistado em 18/07/2011).

De janeiro a março é fixado o defeso, quando são proibidos de coletar o caranguejo. Há fiscalização por parte dos técnicos do IBAMA e do ICMBio para que se evite a captura da espécie, como citado na fala anterior. É durante esse período que buscam atividades complementares com mais frequência, destacando-se a pesca de linha e a coleta de sururu, dentre outras.

Os tiradores afirmam que ficam de cinco a oito dias sem poder trabalhar. No ano de 2012 foram espalhadas na área da RESEX matérias de divulgação do período de defeso, buscando sensibilizar a população e os tiradores em relação ao período de reprodução do caranguejo-uçá. A comercialização é proibida nesses dias, daí a importância de sensibilizar também os consumidores e os agentes nos diferentes elos da cadeia de comercialização do crustáceo.

Nas conversas com os tiradores, o entendimento deles sobre o defeso é de que as decisões são tomadas sem consultá-los e que já ocorreram erros nas datas do defeso. Alguns afirmam que não há a necessidade do defeso, pois os caranguejos se reproduzem em grande quantidade e rapidamente e que existem estratégias de conservação, sendo coletados somente machos e graúdos. "Condurua não, só graúdo. Porque é proibido, elas que "filha" eles [responsáveis pela reprodução da espécie]. Se a gente pega, daqui a uns tempos não tem mais caranguejo pra gente pegar" (G., entrevistado em 18/07/2011).

Outra fala atribui problemas de descumprimento de normas por parte de pessoas de fora. Há, também, referências quanto à captura de fêmeas em alguma proporção: “A RESEX facilitou, ninguém vai, mas outro de fora não respeita defeso e não fica bem, fica no máximo 8 dias sem pegar, vai trabalhando e reservando um pouquinho [de dinheiro para se manter no período da proibição]" (S. L., entrevistado em 13/07/2011).

Em virtude do defeso do caranguejo, os tiradores da Pontinha do Bacuriteua utilizam estratégias para alimentar as famílias durante esse período. Dizem que quando são divulgadas as datas do defeso, na semana anterior há um aumento na produtividade, quando se intensifica a coleta de caranguejos para aumentar a renda e possibilitar a compra de alimentos durante o período parado, fato afirmado na fala anterior. É necessário prestar atenção a essa estratégia do aumento na produtividade, pois se de fato há esse aumento para compensar a parada, ele pode, então, neutralizar em parte os efeitos do defeso, que visa justamente proteger a espécie. 
Além disso, como já afirmado, há a intensificação das atividades complementares, principalmente a pesca de linha para a subsistência; há a dependência em relação aos comerciantes que "fiam" seus produtos para as famílias. Muitas vezes os patrões são donos ou ligados a esses comércios, havendo uma relação de subordinação dos tiradores em relação a esses sujeitos. "Fica difícil, a gente tira fiado no patrão no comércio. Quando trabalha a gente paga" (Z., entrevistado em 08/08/2011).

Maneschy (1993) criticou a fixação de um período de defeso sem levar em consideração "as estruturas econômicas" e a realidade em que estão inseridos os tiradores, incluindo o mercado que possui demandas cada vez maiores de produção do caranguejo. A autora também destacou a importância do conhecimento científico, citando as Ciências Biológicas, para a delimitação desses períodos de defeso, juntamente com os saberes dos tiradores de caranguejo.

Já a segunda etapa do ciclo biológico do caranguejo percebida pelos tiradores é a troca de carapaça ou troca da "camisa", cientificamente conhecida por ecdise. Souto (2008), após pesquisar os pescadores artesanais do município de Acupe, na Bahia, verificou o saber acerca da ecdise; os pescadores relataram que essa troca na carapaça não se dá de maneira simultânea para todos os caranguejos, mas que determinado contingente a realiza e outro não, só vindo a fazê-lo mais tarde, o que permite que a coleta continue em menores quantidades. Souto (2007, p.75) também verificou o saber dos tiradores sobre essa "não sincronia" dos caranguejos na troca da carapaça.

De acordo com Souto (2007), esse período do ciclo biológico do caranguejo implica diretamente na cadeia produtiva. Domingues $(2008$, p.40) também analisa como a troca da "camisa" afeta o trabalho dos tiradores da Vila do Tamatateua, localizada no município de Bragança, onde esses trabalhadores têm que procurar alternativas visando complementar a renda mensal familiar e encontram muitas dificuldades nessa busca. O autor diz que "essas restrições, por sua vez, acabam por estimular a redução dos esforços na dedicação a esta atividade, forçando-os a dedicar-se às outras atividades produtivas", corroborando para o grande número de tiradores que também complementam sua renda com outras atividades.

Alguns tiradores denominam esse período de troca da carapaça como "falha" devido à menor disponibilidade de caranguejos destinados ao consumo humano. Durante esse período os caranguejos "ficam de leite", expressão usada pelos tiradores, e impróprio para o consumo humano a seu ver. Um dos tiradores entrevistados por Souto (2007, p.75) fez o seguinte relato: "Agora vai começar uma fase ruim, ruim! Vai levar no mínimo uns trinta dias aí para o cara sofrer. Porque ele (o caranguejo) tá panhando leite. Quando panha leite, não presta. Ele fica molinho, molinho".

Essa restrição no consumo do caranguejo que "fica de leite", segundo Souto (2007, p.75), dá-se em consequência do alto teor de carbonatos nas vísceras e carne do caranguejo, acarretando um sabor desagradável para o paladar humano e provocando "diarréia e dores abdominais e alterações no sistema nervoso, como letargia e entorpecimento". Os caranguejos nessa fase não são coletados pelos tiradores de caranguejo na Pontinha do Bacuriteua, segundo o que se apurou aqui.

A característica identificada pelos tiradores de que o caranguejo está trocando a "camisa" é a "tapagem" da galeria feita pelo próprio crustáceo, que se aloja e inicia o processo de mudança da carapaça. Os tiradores quando percebem que as galerias estão "tapadas" saem em busca de galerias abertas, sendo uma das características verificadas no momento da escolha dos territórios para a coleta.

A não sincronia dessa etapa faz com que os tiradores continuem indo ao manguezal, porém cai a quantidade de caranguejos coletados. E efetuam maior mobilidade dentro do manguezal, buscando as tocas abertas. "Tem muito tapado e muito destampado. Fica muito

\footnotetext{
${ }^{9}$ Quando os tiradores afirmam que os caranguejos estão tapados significa que a abertura da galeria onde o bicho fica para proceder a troca da carapaça está bloqueada.
} 
difícil, mas quando trocam a casca eles ficam raso (C., entrevistado em 08/08/2011)". Portanto, é um período de grande dinâmica no que tange à atividade extrativista, devido à dependência do tirador em relação aos caranguejos que ainda não iniciaram a troca, ou que já a fizeram, e os que estão passando por esse processo.

Passado o período de troca da "camisa", inicia-se a "safra" do caranguejo, momento em que há grande quantidade de caranguejos disponíveis para a coleta e quando inicia a "engorda" e o crustáceo está mais "graúdo", com casco acinzentado e com a carne de gosto "doce", de acordo com os tiradores. É o período em que aumenta a produtividade e diminui a demanda pelo produto. De um lado, porque já passou o mês de férias e de pico de consumo e, de outro lado, em grande parte dos municípios do nordeste paraense ocorrem os círios municipais, cuja culinária nem sempre engloba o caranguejo, fazendo com que seja o período do ano em que é pago o menor valor pela cambada.

Porém, diferentemente do período da andada, quando os caranguejos se tornam presas fáceis, na fase da safra o comportamento do caranguejo se modifica, tornando-se mais "arisco" e dificultando a sua coleta. Souto (2007) enumera diversas expressões utilizadas pelos tiradores de Acupe, na Bahia, para sinalizar a "esperteza" dos bichos nesse período, tais como: "veiacos", "astúcia" e "tarimba".

Quando se considera a percepção dos tiradores sobre o ciclo biológico do caranguejo há relações diretas entre a produtividade dos trabalhadores e o preço do caranguejo. Durante a andada o preço da cambada é baixo e há a proibição por parte do Estado.

Na safra essa relação se inverte, pois há maior oferta de caranguejo e menor demanda por parte do mercado e, consequentemente, o preço da cambada é menor. "Agora [julho] no máximo 10 cambadas, 8, 9, 7. Em outubro pega 15, 20. Nesse tempo de agora [julho] a gente tá vendendo de $\mathrm{R} \$ 8,00$. A partir de outubro tira mais, mas diminui o dinheiro, a gente vende de $\mathrm{R} \$ 3,00$, de $\mathrm{R} \$ 4,00$ (Q., entrevistado em 18/07/2011)”. Apesar da possível defasagem no texto, o importante é evidenciar as diferenças de preço em relação ao ciclo biológico que interfere na quantidade e tamanho disponível para coleta.

Portanto, os saberes acerca das marés, ciclo biológico do crustáceo, a identificação do tamanho, sexo e as condições dos diferentes espaços próprios dos manguezais são aspectos fundamentais para as estratégias e a organização da atividade extrativista, influenciando em preço, demanda e qualidade do produto, entre outros (DOMINGUES, 2008).

Torna-se mais claro, também, o quanto se constituem elementos que interferem na relação entre esses trabalhadores e os patrões, principalmente, no que tange aos preços praticados na compra das cambadas pelos últimos.

Outro aspecto que influencia na comercialização é o sexo e o tamanho dos caranguejos coletados. De acordo com Domingues (2008, p.35), o mercado é quem regula a seleção dos caranguejos a serem coletados. É estabelecido o preço a ser pago a partir do tamanho do caranguejo, sendo proporcional, ou seja, quanto maior o tamanho maior o preço pago. A compra de fêmeas é restringida. Acerca dessa proporcionalidade do valor pago com o tamanho do crustáceo, Reis $(2007$, p.217) afirma que "os caranguejos pequenos não são recusados pelos comerciantes, mas recebem um preço menor, em relação às cambadas de graúdos”. Os tiradores também recebem o respeito e valorização dos patrões quando são coletadas cambadas com caranguejos graúdos, tendo o objetivo claro de estimular a competição entre tiradores e promover a coleta de caranguejos maiores, mais aceitos no mercado.

Souto (2007) relaciona as preferências nas coletas com o tamanho, sexo e com a estação climática. Os tiradores do município de Acupe buscam coletar machos e graúdos principalmente no verão, mas no inverno, devido a facilidade que os caranguejos têm em escavar as galerias devido ao solo do manguezal se apresentar mais "mole", há maior esforço no trabalho e, com isso, coletam algumas fêmeas. Porém, o autor ressalta que o aspecto mais importante nessa escolha do espécime a ser coletado é o seu tamanho, mais do que o sexo, por 
terem maior aceitação no mercado e maior preço, sendo que "mesmo as fêmeas, quando coletadas, passam por uma seleção de tamanho" (SOUTO, 2007).

Domingues (2008, p.34), a partir dos relatos dos tiradores, identifica as principais diferenças de sexo dos caranguejos elencadas pelos sujeitos em sua pesquisa: o tamanho da carapaça das conduruas é menor que dos machos; "a presença de pêlos em maior ou menor quantidade na região inferior das patas; o perfil mais ou menos delgado da unha (primeiro segmento das patas)"; e o "imbigo" (abdômen), localizado na parte inferior da carapaça, maior nas fêmeas para abrigar os ovos após o acasalamento.

Os tiradores também utilizam caraterísticas na entrada das galerias feitas pelos caranguejos para diferenciar o sexo. Maneschy (1993, p.29) relata que os trabalhadores distinguem as galerias da condurua pelas marcas das patas em torno dos buracos; as "fêmeas deixam sulcos mais finos e profundos" e quando os tiradores se enganam na coleta e apanham uma fêmea imediatamente a soltam, garantindo, na visão destes, a reprodução da espécie, conforme os relatos colhidos pela autora em São Caetano de Odivelas. Domingues (2008) também trata sobre esse assunto dizendo que os machos fazem as galerias com maior circunferência na abertura e deixam rastros mais espessos, devido a seu maior tamanho em relação à condurua. Portanto, em relação à escolha dos territórios para desempenho da atividade extrativista, os tiradores tendem a buscar locais onde exista muitas galerias e com grande circunferência, que configuram a presença de caranguejos machos e graúdos. Em relação aos tipos de caranguejos coletados pelos tiradores da Pontinha do Bacuriteua dois se destacam: o caranguejo cabelo branco e o caranguejo cabelo vermelho.

Eles apontam as seguintes características do caranguejo com cabelo branco: casco com a cor azulada; localizado em áreas com predominância de tijuco mole; unha (pata) com pêlos brancos, daí a denominação de cabelo branco; tem maior concentração de gordura e, portanto, são maiores que o caranguejo com cabelo vermelho; tem o sabor mais adocicado; concentramse no raizal; predominam nas áreas do Rio Taperaçu e do Furo da Ostra, ambas na península bragantina; são considerados mais perecíveis ou "mais fracos", sendo destinados a Bragança e a mercados mais próximos.

Em relação ao de cabelo vermelho, os tiradores da Pontinha do Bacuriteua destacam as seguintes características: casco com a cor entre o vermelho e o preto; localizado em áreas de transição entre terra firme e manguezal; tem a unha (pata) com pêlos vermelhos ou pretos, daí a denominação cabelo vermelho; tem menor concentração de gordura e, portanto, menores que o caranguejo com cabelo branco; são conhecidos como "Puruê"; concentram-se no siribal (pneumatóforos); são predominantes nas áreas do Furo do Taici e Rio Caeté, ambas localizadas próximas da Pontinha do Bacuriteua; considerados menos perecíveis que o de cabelo branco, ou seja, "ele não morre muito", sendo destinados à Bragança e, também, a mercados mais distantes, por sua baixa perecibilidade.

Durante a pesquisa de campo, conversamos com três patrões na Feira principal do município de Bragança e todos concordaram que o cabelo branco é o tipo que mais vendem e todos foram unânimes em afirmar que há dificuldade em comercializar o cabelo vermelho em Bragança, sendo destinados a outros mercados, inclusive o de Belém. Os tiradores afirmam que coletam os dois tipos. Porém, o tamanho maior do caranguejo cabelo branco em relação ao vermelho estimula explorarem mais as áreas onde esse caranguejo tende a prevalecer.

Portanto, para a compreensão da atividade extrativista, suas demandas mercadológicas e os preços praticados entre tiradores e patrões, o saber do ciclo biológico, o sexo e os tipos de caranguejo são fundamentais no que tange à organização social do grupo e sua reprodução. 


\section{CONSIDERAÇÕES FINAIS}

Os principais resultados foram de que os tiradores de caranguejo da Pontinha do Bacuriteua acompanhados se caracterizam por início na atividade extrativista do caranguejo ainda durante a adolescência; alta evasão escolar; pela transmissão geracional da atividade; pela grande experiência na atividade extrativista; estão no ramo há mais de 35 anos; se autorrepresentam como especialistas na atividade, embora também atuem em atividades complementares e têm dificuldade em serem reconhecidos como categoria profissional; enfrentam problemas de saúde geralmente com alguma relação com as condições de seu trabalho; seu regime semanal de trabalho ocorre de terça a sábado, com folga geralmente no domingo e segunda-feira; quanto à organização do trabalho, as formas de coleta mais utilizadas pelos tiradores são o braço e o gancho.

Sobre as implicações e influências dos ciclos biológicos do caranguejo e outras características do ambiente na organização da sua atividade extrativista e produtividade, levando em consideração os conhecimentos tradicionais locais que os tiradores reproduzem, os resultados indicaram que a estacionalidade, juntamente com fatores ligados às marés e ao ciclo biológico do caranguejo, incidem na percepção dos tiradores de caranguejo quanto a facilidade ou dificuldade em coletar o caranguejo, relacionando-se diretamente com a produtividade; o regime de marés é conhecido pelos tiradores de caranguejo da Pontinha do Bacuriteua e necessário para o desempenho de suas atividades, repercutindo diretamente no seu tempo diário de trabalho, nas técnicas e tecnologias utilizadas e, consequentemente, na sua produtividade; a composição do solo relacionada com as árvores presentes no manguezal se apresenta como mais um fator do ecossistema que os tiradores de caranguejo da Pontinha do Bacuriteua levam em conta no momento da escolha das áreas de coleta e a instituição dos territórios temporários.

Resumindo, para a compreensão da atividade extrativista do caranguejo, suas demandas mercadológicas e os preços praticados entre tiradores e patrões, o conhecimento do ciclo biológico, o sexo e os tipos de caranguejo são fundamentais no que tange à organização social do grupo e sua reprodução, pois dependendo desse estágio biológico as relações entre esses grupos, tiradores e patrões, se estabelecem de maneira diferente, afetando a organização do trabalho e os ganhos de renda dos tiradores. Além disso, os conhecimentos sobre o sexo e o tipo de caranguejo e as pressões do mercado terão influência na escolha dos territórios para a prática de suas atividades.

No contexto da pesquisa foram identificadas nas falas dos tiradores de caranguejos: frases, metalinguagens, prosopopeias e outros referenciais que apontam muitos elementos como aprendizagem para os trabalhos no manguezal, pois, de acordo com o grupo: "não se entra de qualquer jeito", são necessárias roupas apropriadas; andanças adaptadas; tocar-se na lama; utilizar o gancho de forma cautelosa para não matar o crustáceo; destreza para agarrar o caranguejo e amarrá-lo ou colocá-lo no saco; saber as horas da vazante e da enchente da maré; observar os solos onde possivelmente há mais crustáceo; o ciclo biológico do caranguejo, etc. Esses são saberes utilizados nas práticas socioambientais que requerem dos trabalhadores aprendizados ao longo do contato com o meio ambiente pelo contato com de pessoas mais experientes na atividade, que ensinaram aos aprendizes técnicas e uso de tecnologias.

O manguezal apresenta-se aos sujeitos pesquisados como lugar das atividades e das reproduções de suas cosmovisões e modos de vida. Esses grupos apropriam-se do território via práticas, regras sociais, modos de manutenção e transmissão de direitos, a partir da construção social e perspectivas, incorporando-o ao seu contexto. Portanto, os esforços do artigo concentraram-se em apresentar como os saberes e práticas socioambientais são utilizados pelos tiradores da pontinha do Bacuriteua em suas atividades diárias à coleta de caranguejos. Esses conhecimentos foram transmitidos de gerações passadas e são utilizados ao manejo no ecossistema costeiro bragantino, o que constituem importante fonte para pensar em ações e/ou 
políticas públicas no território da Resex Marinha caeté-Taperaçu que contextualizem a atividade e evidenciem demandas importantes para esse grupo social.

\section{REFERÊNCIAS}

ACOSTA, Alberto. O viver bem: uma oportunidade para imaginar outros/ Alberto Acosta: tradução de Tadeu Breda. - São Paulo: Autonomia Literária. Elefante, 2016.

ABREU, G. C. de. Conflitos de uso da água nas atividades pesqueiras no baixo rio Solimões Munícipio de Manacapuru-Amazonas-Brasil. In: VII CONGRESSO LATINO-AMERICANO DE SOCIOLOGIA RURAL., 2010, Porto de Galinhas. Anais [...]. Porto de Galinhas, 2010.

ALVES, Alexandre de Brito. "É o jeito vender": coletores, marreteiros e o trabalho no manguezal (Pará-Brasil, 1975-2010). Revista de História da Universidade do Estado de Goiás, Morrinhos, v.4, n. 2, ago./dez.2015. Disponível em: revista.ueg.br. Acesso: 03 jul. 2020 .

ALVES, Alexandre de Brito. Estrada Bragança-Ajuruteua e sobrevivência no manguezal (1975-1991). São Carlos: Pedro \& João Editores, 2020.

ALVES, Alexandre de Brito. PA-458: Território, territorialidade e dinâmica socioeconômica na área costeira de Bragança-PA (Bacuriteua, 1974-2016). Dissertação (Mestrado em Sociologia e Antropologia) - Universidade Federal do Pará (UFPA), Belém, 2017.

BAPTISTA NETO, J. A.; A.; PONZI, V. R.A.; SICHEL, S. E. Introdução à geologia marinha. Rio de Janeiro: Interciência, 2004.

BEGOSSI, A. Áreas, pontos de pesca, pesqueiros e territórios na pesca artesanal. In: BEGOSSI, A. (Org.). Ecologia de pescadores da Mata Atlântica e da Amazônia. São Paulo: Hucitec, 2004, p. 223-254.

CAMPOS, Ipojucan Dias. Cotidiano no manguezal: coletores e estratégias de sobrevivência na natureza, Bacuriteua-Pará (1975-1990). Revista História Oral, v. 1, n. 15, jan.-jun. 2012. Disponível em: revista.historiaoral.org.br. Acesso: 04 jul. 2020.

CAMPOS, Ipojucan Dias. História e Natureza: memórias, sobrevivências, famílias e relações de poder no manguezal (Bragança - PA, 1980 a 1990). Revista Margens (UFPA), v. 7, n. 9, set. 2013. Disponível: php/revistamargens/issue. Acesso: 03 jul.2020.

DIEGUES, Antonio Carlos. Aspectos sócio-culturais e político do uso da água. Texto publicado no Plano Nacional de Recursos Hídricos - MMA, 2005.

DOMINGUES, Denis. 2008. Análise do conhecimento ecológico local e do sistema produtivo como subsídio para gerar instrumentos de gestão da atividade de exploração do caranguejo-uçá (Ucides cordatus Linneaus, 1763) nos manguezais da reserva extrativista Marinha Caeté-Taperaçu, Bragança-PA. Dissertação (Mestrado em Biologia Ambiental) - Universidade Federal do Pará (UFPA), Bragança-PA, 2008.

FURTADO, L. G. 1993. "Reservas pesqueiras" uma alternativa de subsistência e de preservação ambiental: reflexões a partir de uma proposta dos pescadores do médio 
Amazônia. In: FURTADO, L; LEITÃO, W; MELLO, A. F (Org.). Povos das águas: realidade e perspectiva na Amazônia, Belém-PA: Museu Paraense Emílio Goeldi.

FURTADO, L. Problemas ambientais e pesca tradicional na qualidade de vida da Amazônia. In: FURTADO, L. (Org.). Amazônia: desenvolvimento, sociodiversidade e qualidade de vida. Belém, UFPA, NUMA, 1997.

FURTADO, L. G., NASCIMENTO, I. H. do, SANTANA, G., MANESCHY, M. C. A. Formas de utilização de manguezais no litoral do Estado do Pará: casos de Marapanim e São Caetano de Odivelas. Belém: Amazônia: Ci. \& Desenv. v. 1, n. 2, jan./jun.2006.

GLASER, M., CABRAL., N., RIBEIRO, A (Org.). Gente, ambiente e pesquisa: manejo transdisciplinar no manguezal. Belém: NUMA/UFPA, 2005.

HAESBAERT, Rogério. Território e multiterritorialidade: um debate. GEOgraphia, v. 9, n. 17, 2007. Disponível em: periódicos.uff.br. Acesso: 8 ago. 2020.

LEITE, José Leite; LEITE, Eudes Fernandes. Saber formal e saber local: convergências e assimetrias. Ciências \& Cognição, v. 17, n. 2, 2012. Disponível em: http: // www.cienciasecognicao.br. Acesso: 28 set. 2020.

LITTLE, P. E. Territórios Sociais e Povos Tradicionais no Brasil: Por uma Antropologia da territorialidade. Brasília: Série Antropologia nº 322, Ed. UNB, 2002.

LITTLE, P. Territórios sociais e povos tradicionais no Brasil: por uma antropologia da territorialidade. Tempo Brasileiro: Rio de Janeiro, 2004. Disponível em: www.Dan.unb.br. Acesso: 28 set. 2020.

MELLO, A. F. 1993. Pescadores da Indústria: o complexo de Icoaracy. In: FURTADO, L; LEITÃO, W; MELLO, A. F. (Org.). Povos das águas: realidade e perspectiva na Amazônia, Belém-PA: Hucitec.

MANESCHY, M. C. 2003. Sócio-Economia: trabalhadores e trabalhadoras nos manguezais. In: FERNANDES, M. E.B. (Org.). Os Manguezais da Costa Brasileira, pp. 135-164. Maranhão: Fundação Rio Bacanga.

MANESCHY, M. C. 1993. Pescadores no manguezal: estratégias técnicas e relações sociais de produção na captura de caranguejo. FURTADO, L. G; LEITÃO, W; M, A. F. (Org.).

Povos das águas: realidade e perspectivas na Amazônia. Belém: Museu Paraense Emílio Goeldi, p. 19-62.

MCKEAN, M. A. OSTRON, E. Regimes de propriedade comum em florestas: somente uma relíquia do passado?. In: DIEGUES, A. C. E MOREIRA, A. C. C. Espaços e recursos naturais de uso comum. São Paulo: Nupaub/USP, 2001.

NORDI, Nivaldo. Os catadores de caranguejo-uçá (Ucides cordatus) da Região de Várzea Nova (PB): uma abordagem ecológica e social. 1992. Tese (Doutorado em Ecologia e Recursos Naturais) - Universidade Federal do São Carlos (UFSCAR), São Carlos, 1992. 
OLIVEIRA, Marcelo do Vale. "É de quem chegar primeiro": Territorialidades entre tiradores de caranguejos da Vila do Bacuriteua, Bragança/Pa. XV ENCONTRO DE CIÊNCIAS SOCIAIS DO NORTE E NORDESTE e PRÉ-ALAS BRASIL., 2012, Teresina. Anais [...]. Teresina-PI, 2012.

OLIVEIRA, Marcelo do Vale. Trabalho e territorialidade no extrativismo de caranguejos em Pontinha de Bacuriteua, Bragança-Pará. Dissertação (Mestrado em Biologia Ambiental) - Universidade Federal do Pará (UFPA), Bragança, 2013.

OLIVEIRA, Marcus Vinicius. A estrada para o "progresso": política, cultura e natureza em Bragança, Pará (1970-1996). Dissertação (Mestrado em História Social) - Universidade Federal do Pará (UFPA), Belém, 2015.

OLIVEIRA, Marcus Vinicius; HENRIQUE, Márcio Couto. No meio do caminho havia um mangue: impactos socioambientais da estrada Bragança-Ajuruteua, Pará. Revista

Manguinhos, v.25, n.2, abr.-jun. 2018. Disponível em: http:www.revistahcsm.coc.fiocruz.br. Acesso: 9 set. 2020.

SCHAEFFER-NOVELLI, Y. Manguezal: ecossistema entre terra e mar. São Paulo: Carribean Ecological Reserach, 1995.

SILVA, C. N. A percepção territorial-ambiental em zonas de pesca. Belém: Bol. Mus. Para. Emílio Goeldi, Ciências Humanas, v. 2, n. 3, set./dez. 2007, 25-32p.

SILVA, A. L. da. Entre tradições e modernidade: conhecimento ecológico local, conflitos de pesca e manejo pesqueira no rio Negro, Brasil. Belém: Boletim do Museu Paraense Emílio Goeldi, Ciências Humanas, v. 6, n. 1, jan./ abr. 2011, 141-163p.

SCHMIEGELOW, J. M. M. O planeta Azul: Uma Introdução às ciências marinhas. Rio de Janeiro: Interciência, 2004, 202p.

SOFFIATI, Arthur. Da mão que captura o caranguejo à globalização que captura o manguezal. In: II ENCONTRO DA ASSOCIAÇÃO NACIONAL DE PÓS-GRADUAÇÃO E PESQUISA EM AMBIENTE E SOCIEDADE., 2004, Indaiatuba. Anais [...]. Indaiatuba, 2004.

SOUZA, Camilla. 2013. Relações de gênero em Bacuriteua (PA): imaginário do homoerotismo masculino entre coletores de caranguejo. Dissertação (Mestrado em Linguagens e Saberes na Amazônia) - Universidade Federal do Pará (UFPA), Bragança, 2013.

RAMALHO, Cristiano Wellington Noberto. O sentir dos sentidos dos pescadores artesanais. Revista de Antropologia, SÃO PAULO, USP, 2011, v. 54 nº 1. Disponível em http: www.revistas.usp.br/ra/about. Acesso: 28 set. 2020. 